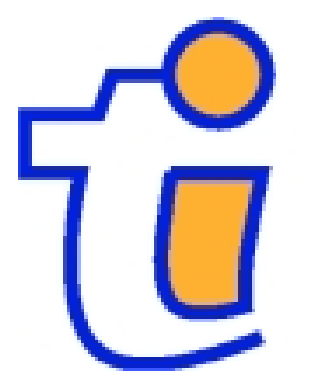

TI 2001-037/2

Tinbergen Institute Discussion Paper

Financial Intermediation and Entry Deterrence

\author{
Neelam Jain \\ Thomas D. Jeitschko \\ Leonard J. Mirman
}


Tinbergen Institute

The Tinbergen Institute is the institute for economic research of the Erasmus Universiteit Rotterdam, Universiteit van Amsterdam and

Vrije Universiteit Amsterdam.

Tinbergen I nstitute Amsterdam

Keizersgracht 482

1017 EG Amsterdam

The Netherlands

Tel.: +31.(0)20.5513500

Fax: $\quad+31 .(0) 20.5513555$

Tinbergen Institute Rotterdam

Burg. Oudlaan 50

3062 PA Rotterdam

The Netherlands

Tel.: $\quad+31 .(0) 10.4088900$

Fax: $\quad+31 .(0) 10.4089031$

Most TI discussion papers can be downloaded at

http://www.tinbergen.nl 


\title{
FINANCIAL INTERMEDIATION AND ENTRY DETERRENCE
}

\author{
Neelam Jain ${ }^{(1)}$ \\ Thomas D. Jeitschko ${ }^{(2)}$ \\ and \\ Leonard J. Mirman ${ }^{(3)}$
}

August 1, 2000

\section{ABSTRACT}

In this paper, we analyze the interaction between an incumbent firm's financial contract with a bank and its product market decisions in the face of the threat of entry, in a dynamic model. The main results of the paper are: there exists a separating equilibrium with no limit pricing; the low-cost incumbent repays more to the bank in the first period, due to the threat of entry; and there are parameter values for which the bank makes more profits with the threat of entry than without.

JEL Categories: D8, G3, L1.

Keywords: Entry, Intermediation, Limit Pricing, Banking, information.

(1) Jesse H. Jones Graduate School of Management, Rice University, MS 531, Houston, Texas 77005, U.S.A.; Tel:1-713-348-5392; Fax: 1-713-348-5251; email: jain@rice.edu.

(2) Department of Economics, Texas A\&M University, College Station, Texas, U.S.A.; Tel: 1-409-845-6929; Fax: 1-409-847-8757; Email: thosd@econ.tamu.edu

(3) Department of Economics, University of Virginia, 114 Rouss Hall, Charlottesville, VA 22903; Tel: 804-9246756; Fax: 804-982-2904; Email: lm8h@virginia.edu. 


\section{INTRODUCTION}

Firms are routinely engaged in financial decision making such as how much to borrow, on the one hand and real decisions such as setting output or price on the other. The effects of both these activities depend on various aspects of the financial institutions and market structure. Existing models in economics and finance provide a good understanding of how real decisions vary with the market structure in the real sector and also provide good insights into the relationship between different institutional frameworks and financial contracting. In these models, however, real and financial decisions are divorced. In the former models, financing decisions are absent while in the latter models, only financing decisions are made. ${ }^{(4)}$ However, the importance of integrating the real and the financial decisions cannot be overemphasized. For example, the profitability of a firm, determined in turn by the market structure in the real sector, has a crucial effect on the nature of the financial contract, just as the latter influences the ability of a firm to undertake good projects, or set better prices and outputs, and thus perhaps even influence the market structure. The presence of private information makes the connection between the real aspects of a firm and its financial contracts all the more significant since lenders may gather information from activities in the real sector and similarly, rivals in the real sector may draw upon financial contracts as sources of information. Recent empirical literature (Chevalier, 1995, Phillips, 1995, for example) shows a growing interest in studying the relationship between the real sector and the financial contracts. For example, Chevalier examines the effect of leveraged buyouts on pricing in supermarket industry and the probability of exit. Similarly there is empirical work that examines the effect of debt on the competitiveness of a firm (for exmaple, Opler and Titman, 1994, Zingales, 1998 and Kovenock and Phillips, 1995).

In this paper, we study the interaction between the financial contracts that a firm enters into, and its incentives and actions to discourage entry, in a dynamic context. Specifically, we study how the financial contract between, say, a bank ${ }^{(5)}$ and a monopolistic, incumbent firm changes, if the latter faces the threat of entry in the second period and how prices, outputs and the extent of entry change, given that the incumbent enters into financial contracts. We allow both the

(4) There are exceptions for example, Bolton and Scharfstein, 1990, Brander and Lewis, 1986, Gertner, Gibbons and Scharfstein, 1988, Maksimovic, 1990, Maksimovic and Titman, 1991, to be discussed later in the introduction.

(5) We use the term 'lender' and 'bank' interchangeably throughout. 
incumbent and potential entrant to have private information about their costs since firms often have private information about their own costs or technology. Such information is valuable to lenders in the financial markets as well as to rivals or potential entrants in the goods markets. Our model enables us to study the role of information in the interaction between the determination of an optimal financial contract and the optimal pricing and output decisions.

Our work is closest to the work by Bolton and Scharfstein (BS), 1990. BS provide important insights into the relationship between predation and financial contracting in a particular environment. We carry their work further in several dimensions. First, we examine the relationship between financial contracting and the incentive of a firm to limit-price and deter entry. Second, we model the pricing and output decisions in the real sector explicitly. Third, we allow firms to have private information about their costs. Thus we study a model that addresses the role of private information in linking the real and the financial sectors as well as provides insights into the effects of adding financial contracting to the standard industrial organization literature on entry-deterrence (see Milgrom and Roberts (MR), 1982 and Matthews and Mirman (MM), 1983). ${ }^{(6)}$

We model the financial relationship as a principal agent relationship between a lender and an incumbent firm, letting the lender be the principal and the incumbent be the agent. ${ }^{(7)}$ The competition between the incumbent and the potential entrant, however, is modelled along the lines of the literature on entry-deterrence, in particular, MR. Thus the incumbent is assumed to have private information about its cost of production, which remains the same in the two periods. He is also assumed to need a fixed amount of loan in each period to operate. For convenience, (and also to capture the competition between a levered and unlevered firm) we assume that the entrant does not need to borrow. However, the entrant is aware that the incumbent borrows. ${ }^{(8)}$

We examine the effect of potential entry on the financial contract chosen by the lender and if entry is actually deterred. We also examine the effect of financial contracting on pricing in the real

\footnotetext{
(6) Gertner, Gibbons and Scharfstein, 1991 also allow private information and link the two sectors as we do through signalling. However, they focus on separating versus pooling linear financial contracts while we study the significance of possible entry for the nature of debt contracts and the impact of debt contracts on limit pricing. In particular, we study only the separating debt contracts.

(7) BS provide a nice rationale for letting the lender be the principal.

(8) BS examine two different scenarios: one, where the rival observes the financial contract and the other where he does not. In our model, since entry occurs in the second period, it is natural to assume that the entrant is aware that the incumbent borrows and of the contracting environment. But we assume that the entrant does not observe the contract.
} 
sector in the first period. In particular, we ask if the incumbent's price in the first period is lowered to discourage entry. We first derive the optimal two-period financial contract without the threat of entry. Then we examine the effect of potential entry in the second period on the financial contract and the effect of the financial contract on the probability of entry and pricing and output decisions of the incumbent. We show that the presence of private information and explicit modelling of the pricing and output decisions lead to significantly different results compared to those in the existing literature on entry-deterrence and finance. For example, limit pricing does not necessarily arise in our model.

In the optimal separating contract of the static case (which does not involve any entry), we find that the low-cost incumbent produces the first-best level of output, and is required to repay less than its profits whereas the high-cost incumbent produces less than the first-best level of output and is required to repay all of its profits to the bank. When the borrowing relationship is repeated over two periods (assuming no threat of entry), the ratchet effect leads to a lower required repayment for the low-cost incumbent in the first period, leaving the output levels and prices unchanged.

The threat of entry in the second period changes the financial contract in an interesting way. Specifically, due to the threat of entry, the ratchet effect is less severe because the low-cost incumbent invites entry in the second period, by mimicking the high cost incumbent and thus lower profits. As a result, the bank does not need to lower the repayment of the low-cost incumbent as much with entry as without. Hence the bank is better off with the threat of entry. However, entry also reduces the profits of the high-cost incumbent in the second period, making the bank worse off. We derive conditions under which the bank is better off in net terms, due to the threat of entry. This result is interesting since the threat of entry is normally associated with lower profits and thus a less creditworthy incumbent. However, we show that when private information is present, increased entry can also have beneficial effects for the lender.

In addition to the changes in the financial contract, we also show that there exists an equilibrium in which there is no limit pricing or predation by the levered firm, in the sense that the incumbent does not increase its output to discourage entry. Indeed, in this equilibrium, the outputs chosen by the two types of incumbent are the same as those without the threat of entry. That 
is, the low-cost incumbent produces the first-best output and the high-cost incumbent produces less than the first-best output. Thus the resulting price level is the same as the monopoly level (without the threat of entry) for the low-cost incumbent and higher than the monopoly level for the high-cost incumbent. This result is in contrast to the work by MR where limit pricing occurs in every equilibrium. Thus one effect of leverage in the model is the possibility that prices are higher than for example in MR. This result is consistent with Chevalier (1995).

The intuition for the absence of limit pricing is that while in the MR model, price of the good is set by an incumbent who knows its own type, in our model, the bank, who does not know the type of the incumbent, chooses the parameters of the financial contract, including the price of the good. Thus in the MR model, in the absence of an agency relationship, the low-cost incumbent chooses a price that the high-cost incumbent cannot mimic in order to discourage entry (This happens in all the separating equilibria.), while in our model, the agency relationship between the bank and the incumbent leads to a contract that separates the types, thus obviating the need for costly limit pricing. In this sense, the financial contract between the bank and the incumbent serves as a signal of the incumbent's types to the entrant.

Further, the contract between the bank and the incumbent is driven by the opposite incentives. That is, it is the low-cost incumbent who wants to mimic the high-cost incumbent and save on the repayment in contrast to the signalling model of MR where the high-cost incumbent has the incentive to mimic the low-cost incumbent to discourage entry. A consequence of these incentives is that the bank finds it worthwhile to have the low-cost incumbent produce optimally and the high-cost incumbent produce less, provided however that the entrant's beliefs about the outputs are consistent. Thus, if the entrant correctly conjectures these outputs, there is no need for costly limit pricing. While correct conjectures by the entrant seem most natural, we also examine the effects of other possible beliefs of the entrant. ${ }^{(9)}$ We find that there are equilibrium beliefs of the entrant for which the bank finds it optimal to limit price. Note that the gain from limit pricing to the bank is deterred entry for the low-cost incumbent in the second period whereas the loss is lower first period profits. There is a range of outputs, at least as high as the first-best level, for the low-cost incumbent that is consistent with the entrant's beliefs as well as with the bank's profit-

(9) This issue is different from the entrant having out of equilibrium beliefs. 
maximization. Thus limit pricing occurs in some equilibria. We characterize the set of separating equilibria with limit pricing by the low-cost incumbent.

Overall, the result of no limit pricing by the levered firm is consistent with the BS result and the general spirit of results in the recent empirical literature that debt makes a firm less aggressive in the sense that the goods prices are higher than without considering debt. However, we show that higher prices do not necessarily imply loss of competitiveness. This is because first, the extent of entry is unchanged compared to the case when the financing decision is ignored (as in MR) or compared to the case where the entrant knows the cost of the incumbent. Second, the bank can profit from entry and thus need not lower the loan amount to the incumbent. Further, while the financial contract is adjusted in our model as well as in $\mathrm{BS}^{(10)}$, the adjustment does not necessarily lead to deterred entry any more than in the case where either there is perfect information or financing is ignored.

The paper is organized as follows: in section 2, we determine the equilibrium financial contract in a static setting; in section 3, we derive the two-period equilibrium financial contract, without the threat of entry; in section 4, we introduce the entry game and solve for the separating equilibrium that has no limit pricing and finally, in section 5, we discuss equilibria with limit pricing.

\section{Model: Static Financial Contract}

In order to study the entry deterrence problem with financial contracting by the incumbent, we first characterize the financial contract without entry in a two-period model. In order to do this, we determine the one-period optimal financial contract between the bank and the incumbent firm. The setting of the problem follows a standard principal-agent problem where the agent's type is private information and both the principal and the agent share the profits resulting from the agent's hidden actions (see Laffont and Tirole, 1993, for example). We model the bank as the principal and the incumbent firm as the agent whose marginal cost of production, $\tilde{c}$, is its private information. It is assumed that the firm's cost can take two possible values, $\underline{c}$ and $\bar{c}$, where $\underline{c}<\bar{c}$. The bank believes that the probability that the incumbent's cost is high is $\theta$. The firm of type $\tilde{c}$

needs to borrow F dollars, in order to produce the output, $\tilde{Q}$. The bank observes the price of the

(10) In BS the adjustment occurs only when the rival observes the financial contract. 
good, $P$ and thus the output since we assume no uncertainty.

The demand function for the real good is given by:

$$
P=a-b Q
$$

where $P$ is the price of the good.

Assumption $a: a-\bar{c}>(\bar{c}-\underline{c}) \frac{1-\theta}{\theta}$

This assumption is made to ensure that the outputs produced by the two types of the incumbent are positive in the static model. Parameters $a$ and $b$ of the demand function are assumed to be common knowledge.

The firm's profits (gross) are

$$
\tilde{V}=(a-b \tilde{Q}-\tilde{c}) \tilde{Q}
$$

where $\tilde{V}$ and $\tilde{Q}$ denote the profits and the output respectively of the firm of type $\tilde{c}$ and $\tilde{c} \in\{\underline{c}, \bar{c}\}$. The firm's net profits are

$$
\tilde{\Pi}=\tilde{V}-\tilde{R}
$$

where $\tilde{R}$ is the repayment required by the bank from the firm of type $\tilde{c}$.

The bank maximizes its expected profits. If the bank knew the firm's type, it would set the repayment to be exactly equal to $\tilde{V}$. Given that it does not know the firm's type, the repayment must be contingent on price $P$ or equivalently output $Q$.

The bank chooses the repayment-output pair for each type, $((\bar{R}, \bar{Q}),(\underline{R}, \underline{Q}))$ to maximize its profits, subject to the constraints that the incumbent of type $\tilde{c}$ accepts the contract (that is, the contract is individually rational) and that it maximizes its profits (net of repayment) by producing $\tilde{Q}$ and repaying $\tilde{R}$ (that is, the contract is incentive-compatible). A separating equilibrium contract is defined to be a repayment schedule $(\tilde{R}, \tilde{Q})$ such that $\bar{Q} \neq \underline{Q}$ and $\bar{R} \neq \underline{R}$. Given this schedule, the incumbent of type $\bar{c}$ maximizes its profits by producing $\bar{Q}$ and the incumbent of type $\underline{c}$ maximizes its profits by producing $\underline{Q}$. 
Formally, a separating equilibrium is a pair $[(\bar{R}, \bar{Q}),(\underline{R}, \underline{Q})]$ that solves the maximization problem $^{(11)}:$

Maximize

$$
-F+\theta \bar{R}+(1-\theta) \underline{R},
$$

subject to

The Individual Rationality Constraint:

$$
\tilde{R} \leq a-b \tilde{Q}-\tilde{c}) \tilde{Q}
$$

\section{The Incentive Compatibility Constraints:}

$$
(a-b \bar{Q}-\bar{c}) \bar{Q}-\bar{R} \geq(a-b \underline{Q}-\bar{c}) \underline{Q}-\underline{R},
$$

and

$$
(a-b \underline{Q}-\underline{c}) \underline{Q}-\underline{R} \geq(a-b \bar{Q}-\underline{c}) \bar{Q}-\bar{R} .
$$

Proposition 1: The low-cost incumbent produces the first-best output and makes positive profits. The high-cost incumbent produces less than the first-best output and makes zero profits.

Proof: Using the standard results from the agency theory, it is straightforward to show that the individual rationality constraint binds for the high-cost incumbent and the incentive compatibility constraint binds for the low-cost incumbent. Note that the binding individual rationality constraint for the high-cost incumbent implies that he makes zero profits, as required for the proposition. We assume that his incentive compatibility constraint does not bind and then verify it in the equilibrium obtained.

Substituting these two binding constraints into the objective function of the bank, for $\underline{R}$ and $\bar{R}$, we obtain

$$
\Pi_{B}=-F+\theta(a-b \bar{Q}-\bar{c}) \bar{Q}+(1-\theta)[(a-b \underline{Q}-\underline{c}) \underline{Q}-(a-b \bar{Q}-\underline{c}) \bar{Q}+(a-b \bar{Q}-\bar{c}) \bar{Q}]
$$

The bank maximizes this by choosing $\underline{Q}$ and $\bar{Q}$. The first order conditions with respect to $\underline{Q}$ and $\bar{Q}$ yield

(11) To ensure that neither type of incumbent chooses an output different from $\bar{Q}$ and $Q$, we make the standard assumption that the repayment required for all outputs different from $\bar{Q}$ and $\underline{Q}$ are higher than the resulting profits. That is, a forcing contract is offered. 


$$
\underline{Q}=\frac{a-\underline{c}}{2 b}
$$

and

$$
\bar{Q}=\frac{a-\bar{c}}{2 b}-\frac{(\bar{c}-\underline{c})(1-\theta)}{2 b \theta} .
$$

Assumption a ensures that these outputs are positive.

From (3) (which holds with equality) and (4), we obtain

$$
\underline{R}=\frac{(a-\underline{c})^{2}}{4 b}-\bar{Q}(\bar{c}-\underline{c})<\frac{(a-\underline{c})^{2}}{4 b}
$$

Thus the low-cost incumbent makes positive profits in the separating equilibrium. It is easy to verify that the incentive compatibility constraint of the high-cost incumbent is satisfied. Hence the result.

In this set-up, the low-cost incumbent has an incentive to mimic the high-cost incumbent because then the maximum he can be asked to repay is the high-cost incumbent's profits, which is lower than the actual profits made by the low-cost incumbent. Thus, in order to separate the types or get the information about the incumbent's cost, the bank must induce the low-cost incumbent with a positive surplus not to mimic the high-cost incumbent. The amount of surplus depends negatively on the output produced by the high-cost incumbent (see (6)). Thus there is a distortion in the equilibrium output of the high-cost incumbent. That is, he produces less than the first-best output. The low-cost incumbent on the other hand produces the first-best output because the bank is interested in maximizing its profits. Thus the presence of private information leads the bank to choose outputs for the incumbent that are less than or equal to the monopoly levels.

In the separating equilibrium the bank gets all the profits of the high-cost incumbent and less than the total profits of the low-cost incumbent. The bank lends if and only if its expected profits are positive. Since repayments derived in the proposition are positive, the bank lends provided the loan amount, $F$ is small enough. We assume that $F$ is sufficiently small to ensure positive expected profits to the bank and thus the bank lends.

\section{Two-Period Analysis: No Entry}


We now consider a sequence of short-term contracts offered by the bank. Thus the bank lends $F$ to the incumbent in the first period, collects repayment at the end of the period, updates its beliefs about the type of the incumbent it is facing and designs a new contract in the second period. Since there is no noise in our model, if a separating contract is implemented in the first period, the bank learns the type of the incumbent and thus offers the full-information contract in the second period. Given this, the static separating contract is no longer an equilibrium since the low-cost incumbent has an incentive to mimic the high-cost incumbent. To be specific, the firstperiod equilibrium contract must now allow a larger surplus for the low-cost incumbent than in the static case. This is the ratchet effect. The intuition is that if the low-cost incumbent produces what he is supposed to under the static separating contract, and repays what he is supposed to, he reveals his type and makes zero profits in the second period. On the other hand, if he mimics the high-cost incumbent, he makes the same profits in the first period, as by producing the output prescribed for him but he hides his type from the bank and repays only the first-best profits made by the high-cost incumbent in the second period. Since the low-cost incumbent makes higher profits due to the cost advantage, he is better off mimicking the high-cost incumbent. Thus his incentive compatibility constraint is violated.

Specifically, the low-cost incumbent's gain in the second period, from mimicking the high-cost incumbent is

$$
\left(a-b \bar{Q}^{2}-\underline{c}\right) \bar{Q}^{2}-\left(a-b \bar{Q}^{2}-\bar{c}\right) \bar{Q}^{2}=(\bar{c}-\underline{c}) \bar{Q}^{2}=\frac{(\bar{c}-\underline{c})(a-\bar{c})}{2 b},
$$

where $\tilde{Q}^{2}$ denotes the output of the incumbent in the second period. Thus in a separating contract, the low-cost incumbent must be compensated for the foregone profits given by (7), by requiring a lower repayment in the first period from him. ${ }^{(12)}$

Once a separating contract is determined for the first period, the bank sets the second period repayments equal to the total profits made by either type of incumbent and these profits (and thus repayments) are maximized by setting the outputs to be the first-best levels.

Finally, the addition of the second period in our noiseless environment has no effect on the first period outputs since the second period profits of the bank are independent of the actual output

(12) Suitable assumptions are made on the parameters to ensure that the high-cost incumbent's incentive compatibility constraint continues to be satisfied. That is, we rule out the 'take the money and run' strategies (see LT). 
levels produced. The following proposition summarizes these results.

Proposition 2: In the equilibrium separating contract of the first period, the bank sets the first period repayments and outputs to be

$$
\begin{gathered}
\bar{R}=(a-b \bar{Q}-\bar{c}) \bar{Q} \\
\underline{R}=(a-b \underline{Q}-\underline{c}) \underline{Q}-(a-b \bar{Q}-\underline{c}) \bar{Q}+(a-b \bar{Q}-\bar{c}) \bar{Q}-\frac{(\bar{c}-\underline{c})(a-\bar{c})}{2 b}, \\
\bar{Q}=\frac{a-\bar{c}}{2 b}-\frac{(\bar{c}-\underline{c})(1-\theta)}{2 b \theta}
\end{gathered}
$$

and

$$
\underline{Q}=\frac{a-\underline{c}}{2 b}
$$

The second period outputs and repayments are

$$
\begin{gathered}
\bar{Q}=\frac{a-\bar{c}}{2 b}, \\
\underline{Q}=\frac{a-\underline{c}}{2 b}, \\
\bar{R}=\frac{(a-\bar{c})^{2}}{4 b}
\end{gathered}
$$

and

$$
\underline{R}=\frac{(a-\underline{c})^{2}}{4 b}
$$

Proof: Given a separating equilibrium in the first period, the bank has full information about the incumbent's costs. Thus the bank is able to set equilibrium outputs at the first-best levels for both types of incumbents and repayments equal to the profits earned .

Given the second period solution, the bank chooses the first period outputs and repayments to maximize its two-period profits. That is, it chooses $\bar{R}, \underline{R}, \bar{Q}$ and $\underline{Q}$ to maximize

$$
-2 F+\theta\left(\bar{R}+\frac{(a-\underline{c})^{2}}{4 b}\right)+(1-\theta)\left(\underline{R}+\frac{(a-\bar{c})^{2}}{4 b}\right)
$$

subject to

\section{The Individual Rationality Constraint:}

$$
\tilde{R} \leq(a-b \tilde{Q}-\tilde{c}) \tilde{Q}
$$




\section{The Incentive Compatibility Constraints: ${ }^{(13)}$}

$$
(a-b \bar{Q}-\bar{c}) \bar{Q}-\bar{R} \geq(a-b \underline{Q}-\bar{c}) \underline{Q}-\underline{R}
$$

and

$$
(a-b \underline{Q}-\underline{c}) \underline{Q}-\underline{R} \geq(a-b \bar{Q}-\underline{c}) \bar{Q}-\bar{R}+\frac{(\bar{c}-\underline{c})(a-\bar{c})}{2 b} .
$$

As in the static contract, the individual rationality constraint for the high-cost incumbent binds and the incentive compatibility constraint for the low-cost incumbent binds. We assume that the incentive compatibility constraint for the high-cost incumbent does not bind and then verify it in the equilibrium obtained. ${ }^{(14)}$ Thus we obtain

$$
\underline{R}=(a-b \underline{Q}-\underline{c}) \underline{Q}-(a-b \bar{Q}-\underline{c}) \bar{Q}+(a-b \bar{Q}-\bar{c}) \bar{Q}-\frac{(\bar{c}-\underline{c})(a-\bar{c})}{2 b},
$$

and

$$
\bar{R}=(a-b \bar{Q}-\bar{c}) \bar{Q}
$$

Substituting these values in the bank's two-period profits, it follows that the first order conditions, with respect to the first-period outputs, do not change compared to the static problem and thus the equilibrium output choices of the two types of incumbent are unaffected by the addition of the second period.

Remark: One of the important features of the two-period separating contract is that the low-cost incumbent pays a lower repayment in the first period, than in the static case, in return for giving up the profits in the second period. As noted earlier, this is called 'the ratchet effect', wherein revealing one's type in the first period leads to more demands in the future periods, thus requiring additional incentives. Secondly, the addition of the second period has no effect on the equilibrium output levels in the first period. This property of the two-period equilibrium has an important bearing on the equilibrium of the entry-deterrence game that follows in the next section.

(13) Note that the high-cost incumbent cannot deviate to the output prescribed for the low-cost incumbent in the first period and then operate in the second period. This is because the bank then regards the high-cost incumbent as the low-cost incumbent in the second period and thus demands a higher repayment than the maximum profits of the high-cost incumbent. We assume that the profits of the first period cannot be used to repay the second period loan.

(14) We impose conditions to rule out the semi-separating equilibrium of LT. 


\section{Entry in the Second Period}

In this section, we introduce the possibility of entry in the second period and examine its impact on the financial contracts between the bank and the incumbent. In particular, we examine whether the threat of entry 'weakens' the incumbent. We also examine how the effects of potential entry, as studied in the industrial organization literature (MR, MM etc.), are affected by the presence of financial contracting. In particular, we are interested in examining the extent to which limit pricing occurs in equilibrium.

The structure of the entry game is similar to that of MR. We assume that the entrant's cost of production $c_{e}$ is also either $\bar{c}$ (high) or $\underline{c}$ (low) and is his private information. Let the bank and the incumbent believe that $c_{e}$ is $\bar{c}$ with probability $\mu$. We now use $c_{i}$ in place of $\tilde{c}$ to denote the cost of the incumbent and assume that the entrant has the same prior beliefs about $c_{i}$ as the bank. We further assume that the entrant incurs a fixed cost of entry $K_{e} \in\{\underline{K}, \bar{K}\}$ where $\bar{K}>\underline{K}$.

Now, following MR, assume that the fixed cost of entry is sufficiently large, for both types of entrants, to make entry profitable only when the incumbent is inferred to be high-cost. That is, if the incumbent's cost were public information, the entrant will enter if and only if the incumbent is high-cost. The entrant observes the price of the good (or equivalently, the output of the good, since there is no uncertainty) in the first period and updates his beliefs about the cost of the incumbent. It chooses whether to enter, on the basis of these updated beliefs. A crucial difference between MR and our model is the presence of financial dealings between the incumbent and the bank. We assume that the entrant is aware that the incumbent borrows from a bank and that the bank does not know the incumbent's costs. This is equivalent to assuming that the entrant can determine the optimal contract conditional on his beliefs.

A separating equilibrium of this two-period model with potential entry in the second period consists of the entrant's decision rule $e *: R^{+} \rightarrow\{0,1\}$ where 0 denotes 'no entry' and 1 'entry', the contract between the bank and the incumbent in the first period, given by $(\bar{Q}, \bar{R}, \underline{Q}, \underline{R})$, the contract between the bank and the incumbent in the second period, given by $\left(\bar{Q}_{2}, \bar{R}_{2}, \underline{Q}_{2}, \underline{R}_{2}\right)$ and the entrant's output $\tilde{Q}^{E}$ if $e *=1$, such that

(i) $\tilde{Q}^{E}$ and the second-period contract $\left(\bar{Q}_{2}, \bar{R}_{2}, \underline{Q}_{2}, \underline{R}_{2}\right)$ are best responses to each other, given the beliefs of the bank and the entrant, about the incumbent's type, implied by the first- 
period contract,

(ii) $e *$ is the optimal response of the entrant to $(\bar{Q}, \underline{Q})$,

(iii) the contract $(\bar{Q}, \bar{R}, \underline{Q}, \underline{R})$ is the optimal response of the bank to $e *$ and

(iv) the entrant's beliefs are consistent with the first-period contract.

Condition (i) requires that the second-period contract between the bank and the incumbent must specify outputs and repayments, consistent with the information gathered by the bank from the first period contract and satisfy the incentive compatibility and individual rationality conditions, taking into account the entrant's output. Further, the entrant's output in the second period must be an optimal response to the output produced by the incumbent in the second period.

Condition (ii) requires that the entry rule of the entrant be optimal (i.e. maximize his expected profits) given the first period output produced by the incumbent, i.e., the entry rule must be optimal given the entrant's beliefs about the incumbent's cost, updated on seeing the first period output.

Condition (iii) requires that the contract between the bank and the incumbent in the first period be individually rational, incentive compatible and an optimal response to the entry rule, that is, it must maximize the two-period expected profits of the bank.

Finally, condiiton (iv) ensures consistency between the entrant's beliefs about the incumbent's type and the outputs specified in the first period contract.

To determine the optimal second-period contract, we start with a particular posterior of the entrant about the type of the incumbent, based on the observed first-period output. We then determine the optimal entry rule. Next, we solve for the optimal second-period contract between the incumbent and the bank, as well as the outputs of the incumbent and the entrant (if entry occurs). This yields the second period profits of the bank, given the entry rule and the beliefs of the entrant. Finally, we work backwards to find the optimal first-period contract between the bank and the incumbent.

The most natural beliefs for the entrant are that the incumbents produce the same outputs as if there were no threat of entry. ${ }^{(15)}$ (We consider other beliefs in the next section.) That is, we assume that the entrant believes the incumbent to be low-cost if he produces output at least

(15) In MR, such beliefs cannot be supported in equilibrium. 
as high as $\underline{Q}$, i.e. $\frac{a-c}{2 b}$, in the first period and high-cost if he produces strictly less than $\underline{Q}$. Then our assumption about fixed costs implies that the entry rule is to enter if and only if the observed output is strictly less than $\underline{Q}$.

Recall from the discussion in the previous section, that if the first-period contract is separating, the bank knows the incumbent's type at the beginning of the second period and thus maximizes its profits in the second period by setting repayments equal to the profits of the incumbent and sets the outputs produced by the two types of incumbents at the first-best levels (in the sense of full-information outputs). The same is true when the threat of entry is added. However, the magnitude of profits to be extracted as repayments in the second period falls due to the possibility of entry. To be specific, in the event of entry, the profits of the incumbent in the second period are (16)

$$
\frac{\left(a-2 c_{i}+c_{e}\right)^{2}}{9 b}
$$

If there is no entry, the profits of the incumbent are

$$
\frac{\left(a-c_{i}\right)^{2}}{4 b}
$$

The entry rule discussed above implies that the bank's second period expected profits are

$$
V=\theta\left[\mu \frac{(a-\bar{c})^{2}}{9 b}+(1-\mu) \frac{(a-2 \bar{c}+\underline{c})^{2}}{b}\right]+(1-\theta)\left[\frac{(a-\underline{c})^{2}}{4 b}\right] .
$$

in the second period.

Given $V$, the bank's maximization problem in the first period is:

Choose $\bar{R}, \underline{R}, \bar{Q}$ and $\underline{Q}$ to maximize

$$
-2 F+\theta \bar{R}+(1-\theta) \underline{R}+\theta\left[\mu \frac{(a-\bar{c})^{2}}{9 b}+(1-\mu) \frac{(a-2 \bar{c}+\underline{c})^{2}}{b}\right]+(1-\theta)\left[\frac{(a-\underline{c})^{2}}{4 b}\right] .
$$

subject to

The Individual Rationality Constraint:

$$
\tilde{R} \leq(a-b \tilde{Q}-\tilde{Q}) \tilde{Q},
$$

(16) We assume that there is complete learning of each other's costs in the event of entry. 
where $\tilde{c} \in\{\underline{c}, \bar{c}\}$ and $\tilde{Q}$ is the output of the incumbent of type $\tilde{c}$ and

The incentive compatibility constraint for the low-cost incumbent:

$$
(a-b \underline{Q}-\underline{c}) \underline{Q}-\underline{R} \geq(a-b \bar{Q}-\bar{c}) \bar{Q}-\bar{R}+(\bar{c}-\underline{c})\left[\mu \frac{(a-\bar{c})}{3 b}+(1-\mu) \frac{(a-2 \bar{c}+\underline{c})^{2}}{3 b}\right] .
$$

The last two terms of the preceding inequality capture the gains of the low-cost incumbent from mimicking the high-cost incumbent in the first period. Note that, unlike in the model without potential entry, here, mimicking the high-cost incumbent is costly since it invites entry.

Note also that it is infeasible for the high-cost incumbent to mimic the low-cost incumbent in the first period and stay operational in the second period, just as in the model without potential entry. This is because if the high-cost incumbent mimics the low-cost incumbent in the first period, the bank believes him to be the low-cost incumbent in the second period and thus demands a repayment that the high-cost incumbent cannot repay. Thus, if the high-cost incumbent mimics the low-cost incumbent, he must 'take the money and run'. However, we rule out such a strategy. Thus the incentive compatibility constraint for the high-cost type is the same as in the static model.

As in the solutions of the previous section, the individual rationality constraint of the highcost incumbent binds and the incentive compatibility constraint of the low-cost incumbent binds. Thus the bank's maximization problem reduces to choosing $\bar{Q}$ and $\underline{Q}$ to maximize

$$
-2 F+\theta(a-b \bar{Q}-\bar{c}) \bar{Q}+(1-\theta)(a-b \underline{Q}-\underline{c}) \underline{Q}-(a-b \bar{Q}-\underline{c}) \bar{Q}+(a-b \bar{Q}-\bar{c}) \bar{Q}-I
$$

where $I=(\bar{c}-\underline{c})\left[\mu \frac{(a-\bar{c})}{3 b}+(1-\mu) \frac{(a-2 \bar{c}+\underline{c})^{2}}{3 b}\right]$ Note that $I$ is a constant. This yields the following proposition.

Proposition 4: In the equilibrium contract in the first period, the output levels chosen by the two types of incumbent are the same as in the static contract and in the two-period model without the threat of entry.

The proof is straightforward and thus omitted.

This result is significant since it implies that there is no limit pricing in this equilibrium, unlike in the MR paper where limit pricing occurs in all equilibria. The intuition for this result is 
that in the MR set-up, the low-cost incumbent could signal its cost only through a higher output (and thus a lower price). In our model, the low-cost incumbent produces a different output than the high-cost incumbent, regardless of entry, due to financial contracting. Thus the potential entrant learns the type of the incumbent on seeing the price of the good since he is aware of the presence of financial contracting. However the exact output levels produced by the two types of incumbents need to be conjectured by the entrant, since he does not observe the contract. In the equilibrium above, we assumed that the entrant correctly conjectures the outputs. In this case there is no need for costly limit pricing since financial contracting already leads to a separation of types. ${ }^{(17)}$ This result shows that the financial characteristics of the incumbent are important as they convey information about the 'real' characteristics of the incumbent to potential entrants.

Furthermore, note that an effect of integrating financial contracts, in an agency-theoretic set-up with private information, with entry-deterrence decisions is to generate first-period output levels that are less than the levels produced by the incumbent in the limit pricing literature where financial contracting is ignored. Equivalently, the price of the good is higher than it would be when financial contracting is ignored. This result is consistent with the findings of Chevalier 1995, in the context of the supermarket industry where an effect of leveraged buyouts is to increase the prices charged by the firm.

Finally, note that the extent of entry remains the same in this particular equilibrium as it is in MR and in an environment of perfect information. That is, given that the entrant correctly conjectures the outputs produced by the incumbents and enters only when the incumbent is highcost, the bank has no incentive to increase the output of the low-cost incumbent (because the entrant does not enter in any case) and the bank would lose more profits than it gains by increasing the output of the high-cost incumbent enough to deter entry. That is, in this equilibrium, the bank does not find it profitable to deter entry. This is in contrast to the result in BS where the lender adjusts the financial contract and dissuades the rival firm from preying. This difference in results indicates the importance of modelling the real sector decisions explicitly.

Our next result deals with the effects of entry on the financial contract. Specifically, we show that the bank finds it optimal to charge a higher repayment from the low-cost incumbent in the first

(17) In the next section, we discuss the possibility of other separating equilibria, consistent with other posterior beliefs of the entrant, that may entail limit pricing. 
period when there is a threat of entry than when there is no such threat. We also find parameter values for which the profits of the bank with the threat of entry are higher than the profits it makes without such threat. These results are interesting for several reasons. First, the results show that the threat of entry alters the financial contract between the bank and the incumbent and thus that it is important to integrate the strategic interaction in the real sector with financial contracting. Secondly, the results show that the bank may be encouraged to lend more to the incumbent (in the sense that a higher loan amount $F$ can be supported in the financial contract) in the presence of a threat of entry and thus 'strengthens' the position of the incumbent. This is in contrast to recent literature on the role of debt (BS, 1990, Chevalier, 1995, Phillips, 1995 etc.). This literature argues that levered firms are more susceptible to predation because it becomes harder for levered firms to borrow. ${ }^{(18)}$ Our model yields conditions in which it is quite the opposite, i.e. there are parameter values where the incumbent is able to borrow more when there is potential entry than when there is none.

These results are summarized in the following propositions. Proposition 5 shows that the threat of entry leads to a higher repayment from the low-cost incumbent in the first period. In Proposition 6, we derive conditions under which the bank makes greater total profits with the threat of entry than without. While the ratchet effect leads to higher profits in the first period for the bank, the second-period profits of the bank fall due to entry.

Let $\underline{R}^{E}$ denote the repayment from the low-cost incumbent with potential entry and $\underline{R}^{N E}$ the repayment without the threat of entry.

Proposition 5: $\underline{R}^{E} \geq \underline{R}^{N E}$.

Proof: Since the outputs are the same in the first period, with or without entry, it suffices to compare the second period gains that the low-cost incumbent stands to make by mimicking the high-cost incumbent, with and without entry. Thus

$$
\begin{aligned}
& \underline{R}^{E} \geq \underline{R}^{N E} \text { if and only if } \\
& \qquad \frac{(\bar{c}-\underline{c})(a-\bar{c})}{2 b} \geq(\bar{c}-\underline{c})\left[\mu \frac{(a-\bar{c})}{3 b}+(1-\mu) \frac{(a-2 \bar{c}+\underline{c})^{2}}{3 b}\right] .
\end{aligned}
$$

(18) In BS for example, even when the lender adjusts the contract to deter predation, the effect of the adjustment is to 'weaken' the firm, since future financing is given with a lower probability. Thus in BS, either the rival preys or the bank withholds funding. 
This inequality reduces to

$$
(\bar{c}-\underline{c})\left[\frac{(a-\bar{c})}{2 b}-\left(\mu \frac{(a-\bar{c})}{3 b}+(1-\mu) \frac{(a-2 \bar{c}+\underline{c})^{2}}{3 b}\right] \geq 0 .\right.
$$

It is straightforward to show that this inequality holds for all values of the parameters. Hence the proposition.

The intuition for this result is that mimicking the high-cost incumbent leads to entry in the second period, reducing the profits of the low-cost incumbent. Thus the bank has to offer the lowcost incumbent a lower incentive not to mimic. This implies a higher repayment from the low-cost incumbent than possible without entry. This result is important since it shows that a threat of entry is not necessarily a profit-reducing event for a lender. It also shows that the presence of private information has an important bearing on whether or not the threat of entry is harmful to the lender. If the bank knew the incumbent's type, the threat of entry would reduce the bank's profits unambigously. However, when the bank does not know the borrower's type, a threat of entry reduces its cost of learning the borrower's type through a lower repayment in the first period (due to the ratchet effect).

The next proposition deals with the overall effect on the bank's profits of the threat of entry. While the expected repayment in the first period increases as shown in Proposition 5, the second period profits of the bank are adversely affected due to entry which occurs when the incumbent is high-cost. Proposition 6 specifies the condition under which the bank benefits from the threat of entry.

Proposition 6: Profits of the bank with potential entry are greater than the profits with no entry if and only if

$$
(1-\theta)\left[\frac{a-\bar{c}}{2 b}-\mu \frac{a-\bar{c}}{3 b}-(1-\mu) \frac{a-2 \bar{c}+\underline{c}}{3 b}\right] \geq \theta\left[\frac{(a-\bar{c})^{2}}{4 b}-\mu \frac{(a-\bar{c})^{2}}{9 b}-(1-\mu) \frac{(a-2 \bar{c}+\underline{c})^{2}}{9 b}\right] .
$$

\section{Proof is straightforward and thus omitted.}

It is clear in the above inequality that if $\theta$ is 'large', the left hand side is close to zero and thus the inequality does not hold. Similarly, for 'small' $\theta$, the inequality holds. Thus the condition 
on parameters is non-trivial. Intuitively, the higher $\theta$ is, the greater is the loss in the second-period profits to the bank due to entry and the lower is the gain due to the ratchet effect payment in the first period. The converse is true as well.

To summarize this section, we have analyzed a particular equilibrium of the combined entrydeterrence and financial contracting game. The results show that modelling financial decisions with private information leads to important changes in outputs and prices in the real sector, while leaving the extent of entry unchanged. We have also shown that adding the entry-deterrence game to financing decisions leads to changes in the financial contract. This section focussed on the case where the entrant correctly conjectures the pre-entry outputs and obviates the need for the bank to limit price. In the following section, we examine the implications of other beliefs of the entrant for limit pricing as well as the financial contracting.

\section{Other Separating equilibria}

In this section, we examine the possibility of other separating equilibria, in particular the ones with limit pricing. We find that there are equilibrium beliefs of the entrant that induce the bank to adjust its outputs (compared to the pre-entry levels) in a way that generates separating equilibria with limit pricing. In these equilibria, the entrant believes that the incumbent is lowcost if and only if the price in the market is strictly below the first-best level that the low-cost incumbent would charge in the absence of a threat of entry. Thus the entrant enters for all prices above (and including) the first-best level for the low-cost incumbent. ${ }^{(19)}$ Given these beliefs of the entrant, the bank must decide whether to offer a financial contract that leads to outputs that are consistent with the entrant's beliefs (that is, limit price) or continue with the pre-entry outputs. Clearly, the bank incurs a cost by limit pricing in the first period and gains by deterred entry for the low-cost incumbent in the second period. It pays to limit price if and only if the gain exceeds the loss. We determine the range of outputs (or equivalently the entrant's beliefs) for which the bank finds it optimal to increase the low-cost incumbent's output beyond the first best level, i.e. it finds it optimal to induce the low-cost incumbent to limit price. ${ }^{(20)}$

(19) Recall that in the separating equilibrium discussed in the preceding section, the entrant believes the incumbent to be low-cost if the price in the market is at most the first-best level.

(20) We leave out the discussion of the case where the entrant believes the cut-off output (price), that is the 
It is straightforward to see that compared to the no-limit pricing equilibrium, the profits of the bank fall since limit pricing leads the bank only to distort its first-period contract to achieve the same profits in the second period as it makes in the previous section. Specifically, in equilibrium with limit pricing by the low-cost incumbent, the repayment from the low-cost incumbent in the first period falls, leaving everything else unchanged.

Separating equilibria with limit pricing are equilibria in which the bank optimally requires the low-cost incumbent to produce more than the first- best output. A necessary condition for this to occur is that the entrant's beliefs about the incumbent's type be consistent with limit pricing. That is, the entrant believes the incumbent to be low-cost if and only if the observed output in the first period is above the first best level. For the sake of concreteness, let the entrant believe that the incumbent is low-cost if and only if the observed output $Q$ is greater than or equal to $Q *$ where $Q *>\frac{a-c}{2 b}$. As in the section above, the entry rule then is such that entry occurs if and only if the observed output in the first period is (strictly) below $Q *$. Given these beliefs of the entrant, the bank's maximization problem amounts to comparing profits from two possible output choices ${ }^{(21)}$ for the low-cost incumbent, while keeping the output of the high-cost incumbent the same as in the other separating equilibrium. These choices are:

(i) $\underline{Q}=\frac{a-\underline{c}}{2 b}$ and

(ii) $\underline{Q} \geq Q^{*}$

Profits under strategy ( $i)$ : Since the entrant believes this output level to be produced by a high-cost incumbent, he enters. Thus the profits of the bank in the second period are:

$$
\left.\Pi_{2}=\frac{1}{9 b} \theta\left[\mu(a-\bar{c})^{2}+(1-\mu)(a-2 \bar{c}+\underline{c})^{2}\right]+\frac{1}{36 b}(1-\theta)\left[\mu(2 a-3 \underline{c}+\bar{c})^{2}+(1-\mu)(2 a-\underline{c}-\bar{c})^{2}\right]\right) .
$$

The first period profits remain the same as in the equilibrium of the previous section since the only change here is that the low-cost incumbent also invites entry in the second period. This has

output below which the entrant enters and above which it does not, to be in-between the pre-entry outputs (prices) produced by the two-types of incumbent. For such beliefs, it can be shown that the low-cost incumbent will continue to produce the first-best output. However, for such beliefs to be supported in equilibrium, we can show that the high-cost incumbent does not limit price. That is, in such equilibria, both incumbents produce outputs at the pre-entry level but the entrant believes the cut-off output to be strictly less than the low-cost incumbent's output and strictly greater than the high-cost incumbent's output. It is clear that in such equilibria, neither the extent of entry, nor the prices and outputs change. Further the financial contract remains unchanged as well.

(21) It is obvious that the other possible choice for the low-cost incumbent's output, namely setting it to be less than $\frac{a-c}{2 b}$ or between $\frac{a-c}{2 b}$ and $Q *$, is dominated by the two choices considered. 
the effect of reducing the bank's profits in the second period if the incumbent is low-cost but has no effect on the financial contract in the first period. In particular, the low-cost incumbent's incentive to mimic the high-cost incumbent remains unaffected and thus the ratchet effect repayment remains the same as before.

Profits from strategy (ii): First, note that the bank will choose not to produce more than $Q *$ since the entry is deterred by producing $Q *$ and the further the bank gets away from the optimal output for the low-cost incumbent, the less are his profits in the first period. Now the bank's profits in the second period given that it sets $\underline{Q}$ to be $Q *$ and $\bar{Q}$ to be as before, are:

$$
\frac{\theta}{9 b}\left[\mu(a-\bar{c})^{2}+(1-\mu)(a-2 \bar{c}+\underline{c})^{2}\right]+\frac{1-\theta}{4 b}(a-\underline{c})^{2} .
$$

Thus by switching to $Q *$, the bank deters entry in the second period for the low-cost incumbent and gains the difference between (9) and (8), i.e.,

$$
G=(1-\theta)\left(\frac{(a-\underline{c})^{2}}{4 b}-\frac{\mu(2 a-3 \underline{c}+\bar{c})^{2}+(1-\mu)(2 a-\underline{c}-\bar{c})^{2}}{36 b}\right)
$$

However, the bank loses in the first period due to a greater than the first- best level of output for the low-cost incumbent. Specifically the loss is given by:

$$
L=(1-\theta)\left[\left(a-b \frac{a-\underline{c}}{2 b}-\underline{c}\right) \frac{a-\underline{c}}{2 b}-(a-b Q *-\underline{c}) Q *\right] .
$$

Note that the ratchet effect repayment is the same as under strategy (i).

The bank limit-prices if and only if $G \geq L$. This inequality reduces to

$$
(a-b Q *-\underline{c}) Q * \geq \frac{\mu(2 a-3 \underline{c}+\bar{c})^{2}+(1-\mu)(2 a-\underline{c}-\bar{c})^{2}}{36 b} .
$$

Let the last term be denoted by $A$. Then it is worth for the bank to limit price if and only if

$$
Q * \in\left(\frac{a-\underline{c}}{2 b}, \frac{a-\underline{c}}{2 b}+\frac{\sqrt{(a-\underline{c})^{2}-4 A b}}{2 b}\right)
$$

and

$$
\mu<\frac{9(a-\underline{c})^{2}-(2 a-\underline{c}-\bar{c})^{2}}{8(\bar{c}-\underline{c})(a-\underline{c})} .
$$


Thus we have the following proposition:

Proposition 7: There exist separating equilibria in which the output of the low-cost incumbent is greater than the first-best output provided the output belongs to the set given by (11) and and provided the probability of the high cost entrant, $\mu$ satisfies (12).

Proposition 7 characterizes the output levels, greater than the first best level, for the low-cost incumbent, that can be supported in separating equilibria of the combined financial contracting and entry-deterrence game studied in this paper. This result is interesting for several reasons. First, it shows that the threat of entry and the potential entrant's beliefs can lead the bank to adjust its financial contract, in a way that deters entry (although the extent of entry is still the same as in an environment of perfect information) and maximizes the bank's profits. Second, it shows that the range of outputs that can be supported in equilibrium is larger than in MR. Thus the addition of financial contracting with private information changes the extent of limit pricing. Loosely speaking, limit pricing here is less since outputs arbitrarily close to the first-best level can be supported in equilibrium. In contrast, in MR, the absence of an agency relationship between the incumbent and the bank, entry-deterrence requires a minimum increase in output above the first best level for the low- cost incumbent. Finally, Proposition 7 shows that as in MR, the entrant's beliefs are crucial in determining the type of the separating equilibrium. However these equilibria differ only in the output produced by the low-cost incumbent in the first period and thus the price of the good and the repayment by him. The effect of entry on the financial contract continues to be the same as studied in the previous section.

\section{Conclusion}

In this paper, we have analyzed the effect of financial contracting between an incumbent firm and a bank, where the incumbent possesses private information about its costs, on the extent of entry, prices and output levels in the real sector. We have also analyzed the effect of the threat of entry in the future on the financial contracting between the bank and the incumbent. Results show that integrating the entry-deterrence game with financial contracting under private information alters the financial contract as well as the prices and outputs. 


\section{REFERENCES}

Bolton, P. and D. Scharfstein (1990), 'A Theory of Predation based on Agency Problems in Financial Contracting, Vol. 80, No. 1, pp. 93-106.

Brander, James and Tracy R. Lewis (1986), 'Oligopoly and Financial Structure: The Limited Liability Effect", American Economic Review, v76, n5, pp. 956-70

Chevalier, J. A. (1995), 'Do LBO Supermarkets Charge More? An Empirical Analysis of LBO's on Supermarket Pricing', Journal of Finance, Vol. 50, No. 4, pp. 1095-1112.

Gertner, R., R. Gibbons and D. Scharfstein (1988), "Simultaneous Signalling to the Capital and Product Markets", Rand Journal of Economics. 19(2): 173-190.

Kovenock, D. and G. Phillips (1995)," Capital structure and product-market rivalry: How do we reconcile theory and evidence?" American Economic Review. 85(2): 403-408.

Laffont, J.J. and J. Tirole (1993), 'A Theory of Incentives in Procurement and Regulation', Cambridge, MA, MIT Press.

Maksimovic, ,"Product Market Imperfections and Loan Commitments", Journal of Finance v45, n5 (December 1990): 1641-53.

Maksimovic and Titman (1991), "Financial Policy and Reputation for Product Quality", Review of Financial Studies v4, n1: 175-200.

Milgrom P. and J. Roberts (1982), 'Limit Pricing and Entry under Incomplete Information', Econometrica, Vol. 50, pp 443-60.

Matthews S. and L. J. Mirman (1983), 'Equilibrium Limit Pricing: The Effects of Private Information and Stochastic Demand', Econometrica, Vol. 51, No. 4, pp. 981-96.

Opler T. and S. Titman (1994), 'Financial distress and corporate performance', Journal of Finance, 49(3): 1015-1040.

Phillips, Gordon M. (1995), 'Increased Debt and Product Market Competition: An Empirical Analysis', Journal of Financial Economics 37, pp. 189-238.

Zingales, L. (1998), "Survival of the Fittest or the Fattest? Exit and Financing in the Trucking Industry", Journal of Finance v53, n3 : 905-38. 